УДК 581.19

\title{
СОСТАВ ГЛИЦЕРИДОВ ОБЛЕПИХОВОГО МАСЛА АЛТАЙСКОГО КРАЯ
}

\author{
() Н.В. Горемыкина, А.Л. Верещагин", Ю.А. Кошелев, Н.С. Першин, А.С. Петров \\ Бийский технологический институт (филиал) Алтайского \\ государственного технического университета им. И.И. Ползунова, \\ ул. Трофимова, 27, Бийск, Алтайский край, 659305 (Россия), \\ e-mail:val@bti.secna.ru
}

Исследован состав глицеридов облепихового масла различных производителей Алтайского края методом газовой хроматографии. Показана возможность прямой дифференциации моно-, ди-, триглицеридов. Установлено, что соотношение индивидуальных видов глицеридов облепихового масла может быть важнейшей, практически не поддающейся фальсификации характеристикой. Показаны преимущества прямого метода определения глицеридов, по сравнению с методом определения жирно-кислотного состава через предварительную пробоподготовку.

Ключевые слова: облепиховое масло, глицериды, ГЖХ, жирно-кислотный состав

\section{Введение}

Моно-, ди-, и триглицериды составляют основную часть большинства растительных масел и кроме пищевой ценности представляют собой (благодаря разнообразному жирно-кислотному составу) прекрасные объекты для исследования. Состав жирных кислот, входящих в глицериды растительных масел, представляет интерес с точки зрения обнаружения различий между маслами разного происхождения [1]. Влияние географического происхождения и стадии созревания на состав триацилглицеридов в ягодах облепихи ранее изучали в работах [2-4].

К настоящему времени для анализа жирно-кислотного состава используется метод газовой хроматографии путем разрушения триглицеридов на отдельные метиловые эфиры жирных кислот, что не дает возможности определить, в какие глицеридные комплексы были связаны жирные кислоты изначально.

Целью настоящей работы является определение состава глицеридов облепихового масла различных производителей Алтайского края.

\section{Экспериментальная часть}

Для исследования были взяты образцы облепихового масла, полученные из облепихи, выращенной в различных районах Алтайского края: Волчихинский, Крутихинский, Змеиногорский, Мамонтовский, Поспелихинский районы, и дикорастущие заросли облепихи в пойме р. Катунь урожая 2013 года. Исследовали образцы облепихового масла следующих производителей Алтайского края: ООО «Ягодное», ООО «Ян-

Горемыкина Наталия Владимировна - аспирант кафедры общей химии и экспертизы товаров Верещагин Александр Леонидович - заведующий кафедрой общей химии и экспертизы товаров, e-mail: val@bti.secna.ru

Кочелев Юрий Антонович - сотрудник кафедры биотехнологии

Першин Николай Степанович - ведущий инженер кафедры биотехнологии

Петров Алексей Сергеевич - инженер кафедры биотехнологии

\footnotetext{
* Автор, с которым следует вести переписку.
} тарное», ЗАО «Алтайвитамины», ООО «Алсу», ООО «Алтайский сад», ООО «Сава».

Подготовка образиов для определения глицеридов. В качестве объектов исследования взяты образцы облепихового масла, полученного экстракцией дифторхлорметаном (хладон 22) из дробленого жома (продукта, получаемого отжатием сока из ягод).

Глицериды жирных кислот определялись методом газовой хроматографии. Образцы для анализа 
готовили по следующей методике: 0,02 г масла растворяли в 5 мл гексана; 0,2 мкл полученного раствора вкалывали в испаритель. Анализ проводился на газовом хроматографе Shimadzu GC-2010 plus при следующих условиях.

Инжектор: температура инжектора $370{ }^{\circ} \mathrm{C}$, поток по колонке 0,75 мл/мин, линейная скорость $33 \mathrm{~cm} / \mathrm{c}$, коэффициент деления 10. Колонка: капиллярная SE-30 «Витохром-м», длина 15 м, внутренний диаметр 0,3 мм, толщина пленки 0,25 мкм, неподвижная фаза - полиметилсилоксан, программирование температуры колонки: изотермический режим 4 мин при начальной температуре $160{ }^{\circ} \mathrm{C}$, затем повышение до $365{ }^{\circ} \mathrm{C}$ со скоростью $8{ }^{\circ} \mathrm{C} /$ мин, время выдержки 15 мин. Общее время анализа 44 мин.

Детектор: пламенно-ионизационный, температура детектора $380{ }^{\circ} \mathrm{C}$, поток воздуха 400 мл/мин, поток водорода 40 мл/мин, поток газа носителя 30 мл/мин, газ-носитель - гелий.

Для идентификацุи триглицеридов использовали стандарты фирмы SUPELCO Cat. No. 17871AMP; МDT12-1KT.

Полученные результаты по глицеридному составу интерпретировали как компоненты, совпадающие по времени удерживания со стандартными веществами. Типичная хроматограмма представлена на рисунке 1. Полученные данные представлены в таблице 1.

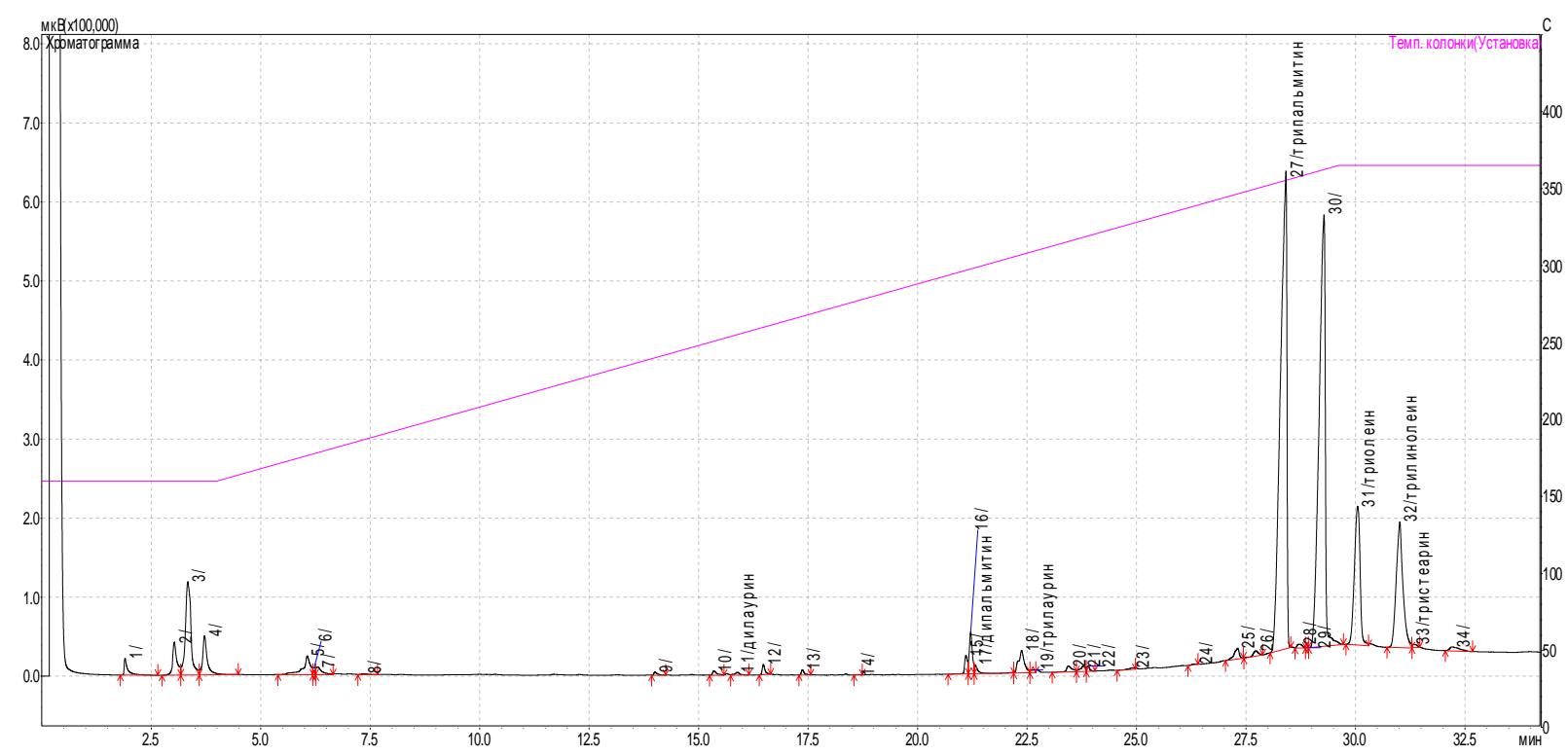

Рис.1. Хроматограмма образца масла облепихового ООО «Алтайский сад»

Таблица 1. Состав компонентов, совпадающих по времени удерживания с глицеридами

\begin{tabular}{|c|c|c|c|c|c|c|}
\hline \multirow[b]{2}{*}{ Компонент, \% } & \multicolumn{6}{|c|}{ Масло облепиховое (100\%) } \\
\hline & $\begin{array}{c}\text { ООО } \\
\text { «Ягодное» }\end{array}$ & $\begin{array}{c}\text { ООО } \\
\text { «Янтарное» }\end{array}$ & $\begin{array}{c}\text { ЗАО } \\
\text { «Алтайвитамины» }\end{array}$ & $\begin{array}{c}\text { ООО } \\
\text { «Алсу» }\end{array}$ & $\begin{array}{c}\text { ООО } \\
\text { «Алтайский сад» }\end{array}$ & ООО «Сава» \\
\hline Монолаурин & - & - & - & - & - & - \\
\hline Мономиристин & - & - & - & $0,02 \pm 0,01$ & - & - \\
\hline Монопальмитин & - & - & - & $0,01 \pm 0,003$ & - & - \\
\hline Моностеарин & - & - & - & - & - & $0,02 \pm 0,01$ \\
\hline Дилаурин & $0,65 \pm 0,13$ & $2,56 \pm 0,04$ & $0,69 \pm 0,14$ & $0,24 \pm 0,04$ & $0,16 \pm 0,02$ & $0,40 \pm 0,06$ \\
\hline Димиристин & $0,03 \pm 0,01$ & - & - & - & - & - \\
\hline Дипальмитин & $1,83 \pm 0,03$ & $0,81 \pm 0,12$ & - & - & $0,37 \pm 0,06$ & - \\
\hline Дистеарин & $0,07 \pm 0,01$ & $0,21 \pm 0,03$ & $0,20 \pm 0,04$ & - & - & $0,06 \pm 0,02$ \\
\hline Трилаурин & $1,57 \pm 0,03$ & $0,55 \pm 0,08$ & $0,74 \pm 0,15$ & $0,30 \pm 0,05$ & $0,14 \pm 0,02$ & $0,18 \pm 0,03$ \\
\hline Тримиристин & - & - & - & $0,02 \pm 0,01$ & - & $0,01 \pm 0,003$ \\
\hline Трипальмитин & $38,46 \pm 0,40$ & $43,56 \pm 0,40$ & $38,16 \pm 0,40$ & $32,47 \pm 0,33$ & $33,39 \pm 0,50$ & $44,70 \pm 0,67$ \\
\hline Триолеин & $7,48 \pm 0,11$ & $7,86 \pm 0,12$ & $9,71 \pm 0,15$ & $13,16 \pm 0,20$ & $8,63 \pm 0,13$ & $8,20 \pm 0,12$ \\
\hline Тристеарин & $1,02 \pm 0,15$ & $0,81 \pm 0,12$ & $0,53 \pm 0,1$ & - & $0,16 \pm 0,02$ & - \\
\hline Трилинолеин & - & - & $7,67 \pm 0,15$ & $18,81 \pm 0,28$ & $9,20 \pm 0,14$ & $0,07 \pm 0,02$ \\
\hline Трипальмитолеин ${ }^{*}$ & $32,34 \pm 0,48$ & $35,14 \pm 0,5$ & $31,28 \pm 0,5$ & $28,63 \pm 0,43$ & $29,06 \pm 0,43$ & $36,67 \pm 0,55$ \\
\hline
\end{tabular}

*предполагаемый триглицерид 
Подготовка образиов для определения жирно-кислотного состава. Объектами исследования выступили те же образцы масла различных производителей. Жирные кислоты превращались в их метиловые эфиры и анализировались на газовом хроматографе «Кристаллюкс-4000».

Определение жирных кислот проводили по следующей методике: 0,02 г масла помещали в колбу вместимостью 100 мл, снабженную обратным холодильником, прибавляли 1 мл метанола, 3 капли ацетилхлорида и нагревали в течение 1 ч на кипящей водяной бане. Затем избыток метанола отгоняли на водяной бане. Остаток растворяли в 0,2 мл гексана и 1 мкл полученной смеси вводили попеременно с модельной смесью в испаритель газового хроматографа с пламенно-ионизационным детектором и хроматографировали в следующих условиях: капиллярная колонка - FFAР 50м, внутренний диаметр 0,32 мм; газ-носитель гелий. Температура термостата была запрограммирована следующим образом: от $180{ }^{\circ} \mathrm{C}$ (изотермический режим в течение 1 мин) до $210^{\circ} \mathrm{C}$ со скоростью $2^{\circ} \mathrm{C} /$ мин, и изотермический период 30 мин при $210{ }^{\circ} \mathrm{C}$. Температура инжектора и детектора $250{ }^{\circ} \mathrm{C}$. Для идентификации жирных кислот использовали СО смеси метиловых эфиров фирмы SUPELCO Cat. No. 07631-1АMP. Полученные данные представлены в таблице 2.

Таблица 2. Состав жирных кислот

\begin{tabular}{l|c|c|c|c|c|c|c}
\hline \multirow{2}{*}{ Кислота, \% } & \multicolumn{5}{c}{ Масло облепиховое (100\%) } \\
\cline { 2 - 7 } & $\begin{array}{c}\text { ООО } \\
\text { «Яодное» }\end{array}$ & $\begin{array}{c}\text { ООО } \\
\text { «Янтарное» }\end{array}$ & $\begin{array}{c}\text { ЗАО } \\
\text { «Алтайвитамины» }\end{array}$ & $\begin{array}{c}\text { ООО } \\
\text { «Алсу» }\end{array}$ & $\begin{array}{c}\text { «лтайский } \\
\text { сад» }\end{array}$ & $\begin{array}{c}\text { ООО } \\
\text { «Сава» }\end{array}$ \\
\hline \multicolumn{7}{|c|}{ Насыщенные жирные кислоты } \\
\hline Миристиновая (С14:0) & $0,57 \pm 0,11$ & $0,76 \pm 0,15$ & $0,87 \pm 0,17$ & $0,32 \pm 0,05$ & $0,41 \pm 0,06$ & $0,38 \pm 0,06$ \\
Пальмитиновая (С16:0) & $36,11 \pm 0,54$ & $34,52 \pm 0,52$ & $36,65 \pm 0,55$ & $24,51 \pm 0,37$ & $31,15 \pm 0,47$ & $34,83 \pm 0,52$ \\
Стеариновая (С18:0) & $1,11 \pm 0,11$ & $1,24 \pm 0,12$ & $1,27 \pm 0,13$ & $2,34 \pm 0,23$ & $1,46 \pm 0,15$ & $1,29 \pm 0,13$ \\
Арахиновая (С20:0) & $0,25 \pm 0,05$ & $0,42 \pm 0,08$ & $0,34 \pm 0,07$ & $0,29 \pm 0,06$ & $0,83 \pm 0,17$ & $0,20 \pm 0,04$ \\
Бегеновая (С22:0) & $0,23 \pm 0,05$ & $0,61 \pm 0,12$ & $0,17 \pm 0,03$ & $0,33 \pm 0,07$ & $0,57 \pm 0,11$ & $0,35 \pm 0,07$ \\
Всего & 38,27 & 37,55 & 39,3 & 27,79 & 34,42 & 37,05 \\
\hline \multicolumn{7}{|c|}{ Мононенасыщенные жирные кислоты } \\
\hline Пальмитолеиновая (С16:1) & $35,98 \pm 0,54$ & $34,57 \pm 0,52$ & $34,45 \pm 0,52$ & $22,38 \pm 0,33$ & $30,83 \pm 0,46$ & $35,33 \pm 0,53$ \\
Олеиновая (С18:1) & $4,34 \pm 0,22$ & $3,04 \pm 0,15$ & $5,78 \pm 0,29$ & $13,21 \pm 0,26$ & $12,93 \pm 0,26$ & $4,19 \pm 0,21$ \\
Вакценовая (С18:1) & $5,64 \pm 0,28$ & $6,81 \pm 0,34$ & $5,76 \pm 0,29$ & $4,74 \pm 0,24$ & $5,19 \pm 0,26$ & $7,56 \pm 0,38$ \\
Всего & 45,96 & 44,42 & 45,99 & 40,33 & 48,95 & 47,08 \\
\hline \multicolumn{7}{|c|}{ Полиненасыщенные жирные кислоты } \\
\hline Линолевая (С18:2) & $11,54 \pm 0,23$ & $12,65 \pm 0,25$ & $12,12 \pm 0,24$ & $27,89 \pm 0,42$ & $13,80 \pm 0,28$ & $11,78 \pm 0,24$ \\
Линоленовая (С18:3) & $0,82 \pm 0,16$ & $1,09 \pm 0,22$ & $0,57 \pm 0,11$ & $1,04 \pm 0,10$ & $1,59 \pm 0,16$ & $0,96 \pm 0,19$ \\
Всего & 12,36 & 13,74 & 12,69 & 28,93 & 15,39 & 12,74 \\
\hline
\end{tabular}

\section{Обсуждение результатов}

Как следует из представленных данных (табл. 1), состав глицеридов облепихового масла различных производителей отличается. Но для всех образцов характерно высокое содержание трипальмитина от 32 до 44\%. Незначительные количества мономиристина 0,02\% и монопальмитина 0,01\% были определены только в образце от производителя ООО «Алсу». Моностеарин был обнаружен только у производителя ООО «Сава», а димиристин - у производителя ООО «Ягодное». Дипальмитин, дистеарин, тримиристин, трилинолеин, тристеарин были обнаружены не во всех образцах. Мы предполагаем, что эти отличия обусловлены тем, что триглицериды облепихового масла существуют как в «чистом» виде (т.е. триглицерид состоит из одной жирной кислоты, как в представленных для идентификации стандартах), так и в «смешанном» виде - когда триглицерид состоит из разных жирных кислот. Идентификация таких триглицеридов затруднена из-за отсутствия стандартов.

Можно предположить, что на 29-й минуте «выходит» пик трипальмитолеина (рис. 2), и для подтверждения был проведен анализ жирных кислот методом газовой хроматографии.

Как следует из представленных данных, состав жирных кислот облепихового масла различных производителей отличается. Но основную долю составляют пальмитиновая кислота (от 24 до 36\%) и пальмитолеиновая кислота (от 22 до 36\%), что подтверждает наше предположение о присутствии значительного количества трипальмитолеина в облепиховом масле.

Сравнительный анализ данных количественного содержания триглицеридов - трипальмитина и трипальмитолеина и жирных кислот - пальмитиновой и пальмитолеиновой представлен в таблице 3. 


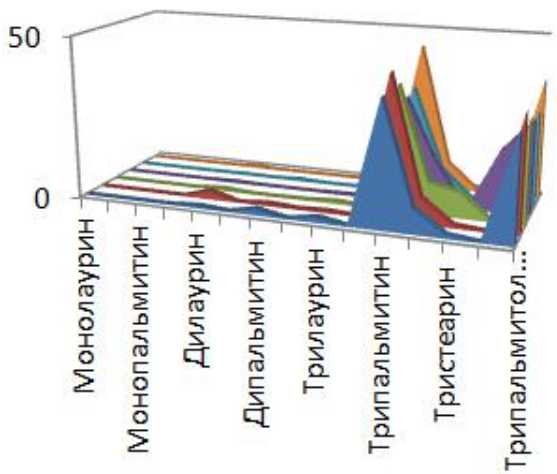

\author{
ш 000 «ягодное» \\ च ООО «Янтарное» \\ - ЗАО «Алтайвитамины» \\ ш 000 «Алсу» \\ ш 000 «Алтайский сад" \\ ш 000 «Сава»
}

Рис. 2. Состав глицеридов

образцов облепихового масла

Таблица 3. Содержание триглицеридов и жирных кислот в образцах облепихового масла различных производителей

\begin{tabular}{l|c|c|c|c|c|c}
\hline \multirow{2}{*}{$\begin{array}{c}\text { Глицерид или } \\
\text { кислота, \% }\end{array}$} & \multicolumn{9}{|c}{ Масло облепиховое (100\%) } \\
\cline { 2 - 7 } & $\begin{array}{c}\text { ООО } \\
\text { «Ягдное» }\end{array}$ & $\begin{array}{c}\text { ООО } \\
\text { «Янтарное» }\end{array}$ & $\begin{array}{c}\text { ЗАО } \\
\text { «Алтайвитамины» }\end{array}$ & $\begin{array}{c}\text { ООО } \\
\text { «Алсу» }\end{array}$ & $\begin{array}{c}\text { ООО } \\
\text { «Алтайский сад» }\end{array}$ & $\begin{array}{c}\text { ООО } \\
\text { «Сава» }\end{array}$ \\
\hline Трипальмитин & 38,47 & 43,56 & 38,16 & 32,47 & 33,39 & 44,70 \\
Пальмитиновая & 36,11 & 34,52 & 36,65 & 24,51 & 31,15 & 34,83 \\
Трипальмитолеин & 32,34 & 35,14 & 31,28 & 28,63 & 29,06 & 36,67 \\
Пальмитолеиновая & 35,98 & 34,57 & 34,45 & 22,38 & 30,83 & 35,33 \\
\hline
\end{tabular}

Из таблицы 3 видно, что представленные данные согласуются между собой, но наряду с этим есть существенные отличия.

Во-первых - содержание трипальмитина во всех образцах больше, чем пальмитиновой кислоты, хотя в анализе данных еще не учитывалось содержание пальмитиновой кислоты в виде моно- и диглицеридов.

Во-вторых - данные по трипальмитолеину в образцах ООО «Ягодное» и ЗАО «Алтайвитамины» ниже, чем пальмитолеиновой кислоты, что также можно объяснить присутствием пальмитолеиновой кислоты в виде других триглицеридов. В то же время в образцах ООО «Алсу» трипальмитолеина больше, чем пальмитолеиновой кислоты.

Таким образом, показана возможность установления глицеридного состава облепихового масла методом газовой хроматографии. Полученные данные свидетельствуют о различном глицеридном составе образцов, произведенных в различных почвенно-климатических условиях Алтайского края, в том числе наиболее важных биологически активных составляющих - полиненасыщенных глицеридов. В связи с этим возникает необходимость разработки требований к глицеридному составу облепихового масла.

\section{Список литературы}

1. Кошелев Ю.А., Агеева Л.Д. Облепиха : монография. Бийск, 2004. 320 с.

2. Vereshchagin A.G., Tsydendambaev V.D. Effect of geographic origin of sea buckthorn on the triacylglycerol composition of its fruits // Bull. Georg. Nattl. Acad. Sci. 2010. Vol. 4. Pp. 92-100.

3. Цыдендамбаев В.Д., Кузнецова Э.И., Пчелкин В.П., Верещагин А.Г. Распределение н-октадеценовых кислот в триацилглицеринах околоплодника созревающих плодов облепихи // Доклады Академии наук. 2011. Т. 436. C. $121-124$.

4. Пчелкин В.П., Кузнецова Э.И., Цыдендамбаев В.Д., Верещагин А.Г. Распределение необычных жирных кислот в триацилглицеринах масла околоплодника облепихи // Физиология растений. 2006. Т. 53. С. 346-354.

5. Mondello L., Tranchida P.Q., Stanek V., Jandera P., Dugo G., Dugo P. Silver-ion reversed-phase comprehensive twodimensional liquid chromatography combined with mass spectrometric detection in lipidic food analysis // Journal of Chromatography. A. 2005. Vol. 1086. N1-2. Pp. 91-98.

6. Resource site for lipid studies. [Электронный pecypc]. URL: http://www.cyberlipid.org/cyberlip/home0001.htm.

7. Buchgraber M., Ulberth F., Anklam E. Capillary GLC: a robust method to characterize the triglyceride profile of cocoa butter - results of intercomparison study // Journal of Agricultural and Food Chemistry. 2004. Vol. 52. Pp. 3855-3860.

8. Buchgraber M., Ulberth F., Emons H., Anklam E. Triacylglycerol profiling by using chromatographic techniques // European Journal of Lipid Science and Technology. 2004. Vol. 106. Pp. 621-648

9. Дайнека В.И., Дайнека Л.А. Исследование триглицеридного состава масла Pinus sibirica Du Tour // Химия природных соединений. 2003. №2. С. 126-128. 
Goremykina N.V., Vereshchagin A.L. ", Koshelev Yu.A., Pershin N.S., Petrov A.S. GLYCERIDE COMPOSITION OF SEA BUCKTHORN OIL ALTAI KRAI

Biysk institute of technology (branch) of The Altay state technical university of I.I. Polzunova, ul. Trofimova, 27, Biisk, 659305, Altay (Russia),e-mail:val@bti.secna.ru

It was studied composition of sea buckthorn oil glycerides of different manufacturers Altai Krai by gas chromatography. It was shown the possibility of direct differentiation of mono-, di-, triglycerides. It was found that the ratio of individual species of sea buckthorn oil glycerides may be the most important, virtually forgery-proof characteristic.

Keywords: sea buckthorn oil , glycerides , GLC fatty acid composition

\section{References}

1. Koshelev Ju.A., Ageeva L.D. Oblepiha: monografija. [Seabuckthorn: a monograph.]. Bijsk, 2004, 320 p. (in Russ.).

2. Vereshchagin A.G., Tsydendambaev V.D. Bull. Georg. Nattl. Acad. Sci. 2010, vol. 4, pp. 92-100.

3. Tsydendambaev V.D., Kuznecova Je.I., Pchelkin V.P., Vereshhagin A.G. Doklady Akademii nauk, 2011, vol. 436, pp. 121-124. (in Russ.).

4. Pchelkin V.P., Kuznecova Je.I., Tsydendambaev V.D., Vereshhagin A.G. Fiziologija rastenij, 2006, vol. 53, pp. 346354. (in Russ.).

5. Mondello L., Tranchida P.Q., Stanek V., Jandera P., Dugo G., Dugo P. Journal of Chromatography. A. 2005, vol. 1086, no. 1-2, pp. 91-98.

6. Resource site for lipid studies. [Electronic resource]. URL: http://www.cyberlipid.org/cyberlip/home0001.htm.

7. Buchgraber M., Ulberth F., Anklam E. Journal of Agricultural and Food Chemistry, 2004, vol. 52, pp. 3855-3860.

8. Buchgraber M., Ulberth F., Emons H., Anklam E. European Journal of Lipid Science and Technology, 2004, vol. 106, pp. 621-648

9. DajnekaV.I., Dajneka L.A. Himija prirodnyh soedinenij, 2003, no. 2, pp. 126-128. (in Russ.).

Received January 18, 2014

Revised May 30, 2014

\footnotetext{
* Corresponding author.
} 
